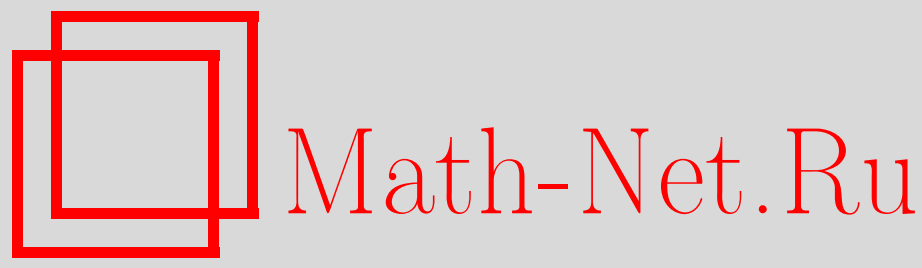

В. П. Маслов, Учет взаимодействия частиц в новой концепции теории нуклеации, ТМФ, 2008, том 156, номер 2, 303-304

DOI: https://doi.org/10.4213/tmf6249

Использование Общероссийского математического портала Math-Net.Ru подразумевает, что вы прочитали и согласны с пользовательским соглашением http://www . mathnet.ru/rus/agreement

Параметры загрузки:

IP: 3.91 .87 .62

26 апреля 2023 г., $11: 57: 07$

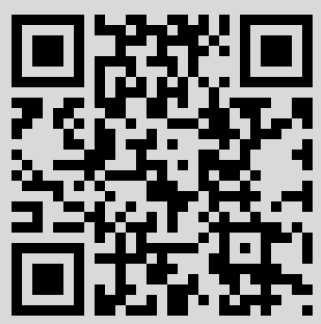




\section{УЧЕТ ВЗАИМОДЕЙСТВИЯ ЧАСТИЦ В НОВОЙ КОНЦЕПЦИИ ТЕОРИИ НУКЛЕАЦИИ}

\footnotetext{
Учет взаимодействия частиц в новой теории нуклеации приводит к фазовому переходу, возникающему в теории Ван-дер-Ваальса.
}

Ключевые слова: нуклеация, сжимаемость, идеальный газ, фрактальная размерность.

Рассмотрим притяжение, описываемое потенциалом Леннарда-Джонса

$$
\Phi(r)=4 \varepsilon\left\{\left(\frac{a}{r}\right)^{12}-\left(\frac{a}{r}\right)^{6}\right\}, \quad r \geqslant a ; \quad \Phi(r)=0, \quad r \leqslant a,
$$

где $\varepsilon$ и $a$ - постоянные, имеющие размерность энергии и длины соответственно; $r^{2}=$ $\left(x_{i}-x_{j}\right)^{2}+\left(y_{i}-y_{j}\right)^{2}+\left(z_{i}-z_{j}\right)^{2}, i \neq j, x_{i}, y_{i}, z_{i}$ - координаты $i$-й частицы. Длина $a$ есть эффективный радиус частицы, при $r=a$ имеем $\Phi(a)=0$. Величина $\varepsilon$ определяет глубину потенциальной ямы $\Phi(r)$ и, следовательно, характеризует интенсивность межмолекулярных сил. Запишем уравнение для одетого потенциала [1]:

$$
U(x)=\int \Phi(x-\xi) \operatorname{Li}_{3 / 2}\left(e^{-b U(\xi)}\right) d \xi
$$

где $\Phi(x-\xi)$ - потенциал $(1)$, a $\mathrm{Li}_{3 / 2}$ - полилогарифм. Его можно переписать, подставив вместо ядра интегрального оператора псевдодифференциальный оператор $\widetilde{\Phi}(i a \partial / \partial x)$, где $\widetilde{\Phi}$ - преобразование Фурье от потенциала взаимодействия. В первом приближении при $a \rightarrow 0$ из соотношения

$$
C=\widetilde{\Phi}(0) \operatorname{Li}_{3 / 2}\left(e^{-b C}\right), \quad \widetilde{\Phi}(0)=\int_{a}^{\infty} \Phi(r) d x d y d z,
$$

где $r^{2}=x^{2}+y^{2}+z^{2}$, может быть определена константа $C$.

При $a^{3} / V \ll 1$, где $V$ - объем, можно полагать, что интеграл (3) берется по отрицательной части потенциала (1). Если $a^{3} N \ll V$, где $N$ - число частиц, то взаимодействием можно пренебречь. Если же его учитывать, то в выражении для химического потенциала возникает добавка, равная $-C$.

Если предположить, что взаимодействие включается лишь при энергии, меньшей, чем глубина $\varepsilon$ потенциальной ямы (1), мы можем воспользоваться формулой для

${ }^{*}$ Московский государственный университет им. М. В. Ломоносова, Москва, Россия. E-mail: v.p.maslov@mail.ru 
давления с учетом этого "скачка". При определенных соотношениях на $C, \mu(V, T)$, $T$ и $\varepsilon$ возникает формула, аналогичная формуле Ван-дер-Ваальса зависимости давления от объема, которая в равновесном состоянии определяет фазовый переход из газообразного состояния в жидкое.

Формула (6) из работы [2], хотя по виду совпадает с распределением Бозе-Эйнштейна, на деле имеет другой смысл. Явление, описанное в [2], похоже на бозе-конденсат: есть, как указывалось в [2], фазовый переход 1-го рода, но это переход, как правило, не в жидкость, поступательная энергия которой очень мала, а в димеры (склеенную пару [3]), и, значит, число частиц (димеров и одиночных частиц) становится меньше, что приводит к возрастанию химического потенциала. Это полностью объясняет известные графики для сжимаемости газов [4], [5]. Теория объясняет также тот факт, что вода в нанотрубке замерзает лишь при нескольких градусах Кельвина, причем температура замерзания зависит от толщины нанотрубки: чем у́же трубка, тем ниже температура замерзания.

В задаче термодинамики есть большой параметр - число частиц. Кроме того, имеется другой большой параметр - объем $V$. Мы рассматриваем удельный объем $V_{\text {уд }}=V / N$. Объем $V$ имеет размерность 3 . Термодинамика также рассматривает двумерную поверхность с большим параметром - числом частиц $N^{2 / 3}$ и удельную поверхность $S / N^{2 / 3}$, где $S$ - площадь поверхности. Очевидно, что между этими двумя целыми размерностями есть и другие нецелые фрактальные размерности, которые получаются, когда удельный объем стремится к нулю.

Иначе говоря, когда объем $V$ есть утолщенная поверхность, толщина которой $D \approx N^{\alpha-1 / 3}$ при $\alpha<1 / 3$ стремится к нулю при $N \rightarrow \infty$, при $\alpha=0$ получается поверхность $S$. Величина $\alpha$ определяет промежуточную (фрактальную) размерность между 3 и 2. Если речь идет о газе, то реально она может быть определена наличием нанопор в веществе и их объемом.

Максимальное число частиц в перенасыщенном газе (паре) в трехмерном объеме определяется из распределения типа Бозе-Эйнштейна. Для случая двумерной поверхности оно равно бесконечности. Однако для промежуточной размерности, определенной наличием нанопор, оно конечно и стремится к бесконечности при размерности, стремящейся к 2. Если газ перенасыщенный при фиксированной достаточно низкой температуре, то может образовываться жидкость с нанопузырями, и размерность может резко упасть при увеличении давления, а следовательно, может упасть сжимаемость.

\section{Список литературы}

[1] В. П. Маслов, Матем. заметки, 83:6 (2008), 864-879.

[2] В. П. Маслов, ТМФ, 156:1 (2008), 159-160.

[3] В. П. Маслов, ТМФ, 125:2 (2000), 297-314.

[4] А.И. Бурштейн, Молекулярная физика, Наука, Новосибирск, 1986.

[5] Citizendium, "Compressibility factor (gases)", http://en.citizendium.org/wiki/Compressibility_factor_(gases). 